\title{
The safety profile of parecoxib for the treatment of postoperative pain: a pooled analysis of 28 randomized, double-blind, placebo-controlled clinical trials and a review of over 10 years of postauthorization data
}

This article was published in the following Dove Press journal: Journal of Pain Research

10 October 2017

Number of times this article has been viewed

\author{
Stephan A Schug ${ }^{1,2}$ \\ Bruce Parsons ${ }^{3}$ \\ Chunming $\mathrm{Li}^{4}$ \\ Feng $\mathrm{Xia}^{5}$
}

'Pharmacology, Pharmacy and Anaesthesiology Unit, School of Medicine and Pharmacology, University of Western Australia, Perth, WA, Australia; ${ }^{2}$ Department of Anaesthesia and Pain Medicine, Royal Perth Hospital, Perth, Australia; ${ }^{3}$ Medical Affairs/Global Innovative Products, Pfizer, New York, NY, USA; ${ }^{4}$ Global Innovative Products Statistics, Pfizer, Madison, NJ, USA; ${ }^{5}$ Safety Surveillance and Risk Management, Worldwide Safety and Regulatory, Worldwide Research and Development, Pfizer, New York, NY, USA
Background: Nonselective, nonsteroidal anti-inflammatory drugs (NSAIDs) and selective cyclooxygenase-2 (COX-2) inhibitors are associated with safety issues including cardiovascular, renal, and gastrointestinal (GI) events.

Objective: To examine the safety of parecoxib, a COX-2 inhibitor, for the management of postoperative pain.

Design: Pooled analysis of 28 placebo-controlled trials of parecoxib and review of postauthorization safety data.

Main outcome measures: Prespecified safety events commonly associated with COX-2 inhibitors and/or NSAIDs. In the clinical trial analysis, the frequency of each event was compared between treatment groups using a chi-square test. In the postauthorization review, the number of confirmed cases, along with outcome, was presented for each event.

Results: In the clinical trial analysis, GI-related events occurred in $\sim 0.2 \%$ of patients in the parecoxib and placebo groups. Renal failure and impairment was similar between parecoxib $(1.0 \%)$ and placebo $(0.9 \%)$. The occurrence of arterial (parecoxib $=0.3 \%$; placebo $=0.2 \%$ ) and venous (parecoxib $=0.2 \%$; placebo $=0.1 \%$ ) cardiovascular embolic and thrombotic events was similar between groups. Hypersensitivity reactions including anaphylactic reactions (parecoxib $=8.7 \%$; placebo $=8.6 \%$ ), hypotension ( arecoxib $=2.6 \%$; placebo $=2.1 \%$ ), angioedema (parecoxib $=2.5 \%$; placebo $=2.8 \%$ ), and severe cutaneous adverse reactions ( $0 \%$ in both groups) were similar between groups. Incision site or other skin/tissue infections occurred in $<0.1 \%$ of patients in both groups. The occurrence of these events (total reports/serious reports) in the postauthorization database, based on $69,567,300$ units of parecoxib, was as follows: GI ulceration-related events (35/35), renal failure and impairment (77/68), cardiovascular embolic and thrombotic events (66/64), hypersensitivity reactions including hypotension-related events (32/25) and severe cutaneous adverse events (17/17), and masking signs of inflammation (18/18). A majority of reported outcomes were classified as recovered or recovering.

Conclusions: Potentially serious safety events occur infrequently with parecoxib, which highlights its safety in patients with postoperative pain.

Keywords: Parecoxib, postoperative pain, safety

\section{Introduction}

Nonsteroidal anti-inflammatory drugs (NSAIDs) inhibit cyclooxygenase (COX) enzymes responsible for the synthesis of prostaglandins that mediate pain and
Correspondence: Stephan A Schug Anaesthesiology Unit, University of Perth WA 6847, Australia

$\mathrm{Tel}+61892240201$

Fax +6I 892240279

Email Stephan.schug@uwa.edu.au 
inflammation. ${ }^{1,2}$ As a result, NSAIDs are commonly used in the postoperative setting for the management of pain following surgery. ${ }^{3-5}$

Traditional nonselective NSAIDs that inhibit both COX-1 and COX-2 are associated with a variety of adverse effects, including impaired platelet function and increased perioperative bleeding and blood loss. ${ }^{6}$ Irritation of the gastrointestinal (GI) mucosa is also common and can lead to potentially serious complications of nonselective NSAIDs. ${ }^{7-9}$ While COX-1 is constitutively expressed throughout the body including the stomach, where it plays a role in the protection of mucosal lining, COX-2 expression is mostly limited to sites of inflammation. ${ }^{2}$ Thus, the use of COX-2-selective NSAIDs (COX-2 inhibitors) results in an analgesic benefit equivalent to that of nonselective NSAIDs with less risk of detrimental GI effects. ${ }^{5,9-12}$ More importantly in a surgical setting, COX-2 inhibitors do not affect platelet aggregation and pose less risk for perioperative bleeding compared with nonselective NSAIDs. ${ }^{13,14}$ However, both COX-2 inhibitors and nonselective NSAIDs have the potential to elicit other adverse effects, including, but not limited to, renal failure and impairment, cardiovascular events, and a variety of hypersensitivity or allergic reactions. ${ }^{15-21}$

The COX-2 inhibitor parecoxib is an injectable parenteral prodrug of valdecoxib. Parecoxib is approved in over 80 countries as perioperative analgesia to prevent or reduce postoperative pain and, in some of these countries, it is approved for the treatment of acute pain. ${ }^{22,23}$ It may also be administered in combination with opioids to reduce postoperative opiate requirements. Parecoxib first received regulatory approval in 2001. Thus, a wealth of clinical trial data are available that examine the efficacy and safety of parecoxib in a controlled clinical setting. Postauthorization safety data are available, spanning over 10 years, which examine the use of parecoxib in real-world conditions.

The objective of the current study was to utilize both the large clinical trial and postauthorization databases to summarize the occurrence of predefined safety events, commonly associated with COX-2 inhibitors and/or traditional NSAIDs in patients treated with parecoxib for postoperative pain. Together, these clinical and postauthorization analyses will characterize the safety of parecoxib for the acute management of postoperative pain.

\section{Methods}

\section{Ethics}

Each of the original studies included in this analysis was approved by the appropriate Institutional Review Board, and written informed consent was obtained from all subjects.

\section{Clinical trial registration}

The trials in this analysis were performed from 1997 to 2004 and, as such, are not subject to International Committee of Medical Journal Editors registration requirements. However, two studies included in this analysis are registered on clinicaltrials.gov (NCT00636064; NCT00651300).

\section{Clinical trial analysis}

Data were pooled from 28 randomized, placebo-controlled clinical trials of parecoxib for the treatment of postoperative pain (Pfizer, data on file, 1998, 2000, 2002-2004). ${ }^{24-41}$ Trials were identified from a Pfizer database and were included in the analysis, regardless of outcome, if they were a Phase II or III, randomized, double-blind, placebo-controlled trial. Eleven Phase II or III trials were excluded for not meeting the placebo-controlled or double-blinded criteria. The 28 trials included spanned the years 1997-2004 and included orthope$\operatorname{dic}(n=11)$, dental $(n=5)$, general $(n=1)$, coronary artery bypass grafting (CABG; $n=2)$, gynecologic $(n=5)$, cholecystectomy $(n=2)$, abdominal $(n=1)$, and elective outpatient $(n=1)$ surgeries. These studies include all Pfizer-sponsored, randomized, placebo-controlled trials of parecoxib for the management of postoperative pain that have been conducted as of July 2017. Overall, most studies shared similar key exclusion criteria, which included age of $<18$ years; pregnancy or active lactation; recent or active GI ulceration; diagnosis of, treatment of, or remission from cancer other than basal cell carcinoma in the last 6 months; a history of hypersensitivity to NSAIDs, other COX inhibitors, or opioids; known recent alcohol, analgesic, or narcotic substance abuse; and volume depletion in the opinion of the investigator. All studies prohibited the use of certain medications, particularly analgesics, in the hours (typically, 6-24 h) prior to administration of study medication. Unless part of the protocol or routine preoperative analgesia prohibited medications, many but not all trials included tricyclic antidepressants, opioids, NSAIDs, COX-2 inhibitors, corticosteroids, tranquilizers, neuroleptics, antipsychotics, and antihistamines.

Patient demographics were summarized descriptively according to treatment groups. The frequency of prespecified safety events, commonly associated with the use of COX-2 inhibitors and/or traditional NSAIDs, was calculated and compared between placebo and parecoxib groups using a chi-square test. The relative risk (parecoxib vs placebo) and associated $95 \%$ confidence interval were presented for each safety event. These events of interest occur infrequently, and several types of surgical models were included in the analysis. Therefore, in addition to the primary analyses based on relative risk and chi-square comparisons, supplemental 
analyses of the clinical trial data were performed to determine the weighted risks for each predefined safety event and the risk difference between parecoxib and placebo groups using a Mantel-Haenszel method adjusting for study. ${ }^{42}$ Medical Dictionary for Regulatory Activities (MedDRA) terminology was used to search the clinical trial database for identification of prespecified safety events.

\section{Postauthorization analysis}

In addition to the clinical trial data analysis, a review of available postauthorization safety data for parecoxib was also performed. It is estimated that $69,567,300$ standard units of parecoxib were sold worldwide from the first quarter of 2002 through the first quarter of 2014. Safety data were derived from a Pfizer database that captures and stores all reported adverse event (AE) information from across the world. AEs are coded to a specific MedDRA term and the database was searched for specific MedDRA high-level terms (HLTs), preferred terms (PTs), or standard MedDRA queries (SMQs) corresponding to prespecified safety issues discussed in this article. The number of medically confirmed cases, along with outcome, through March 31, 2014, was presented for each prespecified safety event. Each individual case was categorized as medically confirmed or nonmedically confirmed based on guidelines from the European Medical Agency guidelines on good pharmacovigilance practices (module VI) and the International Conference on Harmonisation (E2B).

Although physicians report AEs they deem related to parecoxib treatment, there is no placebo for direct comparison in the postauthorization analysis. Further, patients often receive other medications, in addition to parecoxib, that may contribute to the event in question and key information is often missing, including age, dose, and duration of treatment. Finally, medical and surgical comorbidities of patients can contribute to the occurrence of AEs. Because of these factors, it is difficult to definitively attribute these events and their outcomes, including fatalities, to parecoxib. The postauthorization analysis, however, is useful to examine broad trends and identify any potentially serious issues related to parecoxib safety that may or may not have been evident in the clinical trial program.

\section{Results}

\section{Patient demographics and exposure to parecoxib in the 28 randomized controlled trials}

In total, 3885 patients received placebo and 5402 patients received parecoxib in the 28 randomized controlled trials. Patient demographics in the placebo and parecoxib treatment groups are shown in Table 1. Exposure to parecoxib during the 28 trials is summarized in Table 2. The most common doses received were 40,20 , or $80 \mathrm{mg}$, which were received by $55 \%, 17 \%$, and $12 \%$ of patients in the parecoxib group, respectively. Overall, exposure to parecoxib in the clinical trial setting largely parallels real-world parecoxib prescribing guidelines that recommend a 20 or $40 \mathrm{mg}$ intravenous (IV) or intramuscular dose, followed every $6-12 \mathrm{~h}$ by 20 or $40 \mathrm{mg}$ doses, as required, not to exceed $80 \mathrm{mg} /$ day for a typical duration of 3-7 days. ${ }^{22,23}$ Single doses of 1, 2, or 5

Table I Patient demographics

\begin{tabular}{lll}
\hline Characteristic & Parecoxib $(\mathbf{N}=\mathbf{5 , 4 0 2})$ & Placebo $(\mathbf{N}=\mathbf{3 , 8 8 5})$ \\
\hline $\begin{array}{l}\text { Sex, } \mathrm{n}(\%) \\
\quad \text { Male }\end{array}$ & $2,087(38.6)$ & $\mathrm{I}, 85 \mathrm{I}(47.6)$ \\
$\quad$ Female & $3,315(61.4)$ & $2,034(52.4)$ \\
Race, $\mathrm{n}(\%)$ & & \\
$\quad$ White & $4,24 \mathrm{I}(78.5)$ & $3,150(81 . \mathrm{I})$ \\
Black & $349(6.5)$ & $202(5.2)$ \\
Hispanic & $264(4.9)$ & $95(2.4)$ \\
Asian & $186(3.4)$ & $168(4.3)$ \\
Other & $136(2.5)$ & $120(3.1)$ \\
N/A & $226(4.2)$ & $150(3.9)$ \\
Age & & \\
Mean (SD) & $46.7(18.2)$ & $51.8(16.1)$ \\
Range & $18-96$ & $18-90$ \\
\hline
\end{tabular}

Abbreviation: N/A, not available.

Table 2 Summary of exposure to parecoxib in the 28 randomized placebo-controlled trials

\begin{tabular}{ll}
\hline Duration of exposure & Number of patients $\mathbf{N}=\mathbf{5 , 4 0 2})$ \\
\hline Cumulative up to 3 days & 4,763 \\
Cumulative up to 7 days & 5,402 \\
Dose administered ${ }^{\text {a }} \mathrm{mg}$ & \\
I & 102 \\
2 & 101 \\
5 & 102 \\
10 & 101 \\
20 & 903 \\
40 & 2,987 \\
50 & 51 \\
60 & 364 \\
80 & 640 \\
100 & 51 \\
Number of administrations & \\
I & 2,282 \\
2 & 450 \\
3 & 295 \\
4 & 407 \\
5 & 224 \\
6 & 1,292 \\
7 & 247 \\
8 & 78 \\
9 & 6 \\
10 & 121 \\
\hline
\end{tabular}

Notes: Includes any mode of administration (intramuscular, intravenous). 
$\mathrm{mg}$ were received by patients in trials for the management of postdental surgery pain.

\section{Gl-related events}

Prostaglandins play an important role in maintaining GI mucosal integrity by producing mucus, stimulating bicarbonate production, decreasing acid production, and maintaining mucosal blood flow. ${ }^{43}$ COX-1 is constitutively expressed in the GI system and, as a result, the use of nonselective NSAIDs poses a significant risk of GI ulceration and bleeding. ${ }^{7-9}$ In contrast, COX-2 is not expressed in the GI system, and the risk of GI-related events is low with COX-2 inhibitors. ${ }^{13,14}$ Indeed, the frequency of GI-related events was $\sim 0.2 \%$ in both the parecoxib and placebo groups in our analysis of 28 controlled clinical trials (Table 3 ). Additionally, only 35 cases of GI-related events were evident in the postmarketing analysis (Table 4). Where an outcome was known $(n=23)$, a majority of patients were recovered or recovering $(n=15)$. Four fatalities were reported in the postauthorization analysis.

\section{Renal failure and impairment}

Both COX-1 and COX-2 are expressed in different structures in the kidney and play a role in regulating a variety of renal processes, including salt and water retention/elimination and overall electrolyte balance. ${ }^{10,19,44}$ Thus, there is a risk of renal failure or impairment with the use of nonselective NSAIDs or COX-2 inhibitors. ${ }^{10,15,19,44}$ However, we found that the frequency of renal failure and impairment was low and comparable between parecoxib (1.0\%) and placebo $(0.9 \%)$ groups in our analysis of the pooled clinical trial data (Table 3$)$. In the postmarketing analysis, over half $(n=41)$ of all medically confirmed cases $(n=77)$ of renal failure and impairment were classified as recovered or recovering at the time of review (Table 4). Six fatalities were reported in the postauthorization analysis.

\section{Cardiovascular embolic and thrombotic events}

Cardiovascular events have been associated with the use of both nonselective NSAIDs and COX-2 inhibitors. ${ }^{9,16,20,21}$ Possible overlapping mechanisms that may explain these cardiovascular effects include increased blood pressure, inhibition of renal function, and reduced production of vasculoprotective prostacyclin in the arterial endothelium as well as alteration of the prostacyclin/thromboxane balance. ${ }^{45}$ The occurrence of various cardiovascular embolic and thrombotic events was low $(<1 \%)$ in both the parecoxib and placebo treatment groups in our analysis of the clinical trial database, which included two trials in CABG surgery (Table 3). These results are consistent with findings from a previous meta-analysis of the cardiovascular safety of parecoxib in the postoperative setting. ${ }^{46}$

Most cardiovascular events have been associated with long-term use of nonselective NSAIDs or COX-2 inhibitors.

Table 3 Occurrence of important safety risks during the 28 randomized placebo-controlled trials

\begin{tabular}{|c|c|c|c|}
\hline Risk & Parecoxib (\% of patients) & Placebo (\% of patients) & $\mathbf{R R}(95 \% \mathrm{Cl})$ \\
\hline \multicolumn{4}{|l|}{ GI-related event ${ }^{\mathrm{a}}$} \\
\hline Hemorrhage & 0.1 & 0.2 & $0.96(0.33,2.76)$ \\
\hline Perforation & 0.0 & $<0.1$ & - \\
\hline Ulceration & 0.1 & $<0.1$ & $2.52(0.52,12.11)$ \\
\hline Renal failure and impairment ${ }^{\mathrm{b}}$ & 1.0 & 0.9 & $\mathrm{I} .14(0.75, \mathrm{I} .75)$ \\
\hline \multicolumn{4}{|l|}{ Cardiovascular thrombotic event ${ }^{c}$} \\
\hline Arterial & 0.3 & 0.2 & $\mathrm{I} .44(0.65,3.20)$ \\
\hline Venous & 0.2 & 0.1 & $\mathrm{I} .44(0.49,4.2 \mathrm{I})$ \\
\hline Mixed or unspecified & 0.2 & 0.2 & $\mathrm{I} .44(0.54,3.83)$ \\
\hline \multicolumn{4}{|l|}{ Hypersensitivity reaction } \\
\hline Anaphylactic (all types) ${ }^{d}$ & 8.7 & 8.6 & I.0I $(0.88,1.15)$ \\
\hline Hypotension ${ }^{\mathrm{e}}$ & 2.6 & 2.1 & $1.25(0.96,1.64)$ \\
\hline Angioedema (all types) ${ }^{f}$ & 2.5 & 2.8 & $0.88(0.68,1.23)$ \\
\hline Severe cutaneous reaction ${ }^{g}$ & 0 & 0 & - \\
\hline \multicolumn{4}{|l|}{ Masking signs of inflammation } \\
\hline Skin and soft tissue infections ${ }^{h}$ & 0 & $<0.1$ & - \\
\hline Incision site infection ${ }^{i}$ & $<0.1$ & 0 & - \\
\hline
\end{tabular}

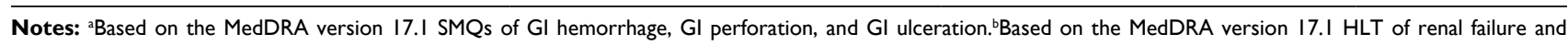
impairment. 'Based on the MedDRA version 17.I SMQs of embolic and thrombotic events arterial, embolic and thrombotic events venous, and embolic and thrombotic events vessel type unspecified and mixed arterial and venous. 'Based on the MedDRA version I7.I SMQ of anaphylactic reaction. ${ }^{\mathrm{B} B a s e d}$ on the MedDRA version I7.I PT of hypotension. 'Based on the MedDRA version I7.I SMQ of angioedema. ${ }^{\text {BBased }}$ on the MedDRA version I7.I SMQ of severe cutaneous adverse reactions. ${ }^{\mathrm{h}}$ Based on the MedDRA version 17.I HLT of skin structures and soft tissue infections. 'Based on the MedDRA version I7.I PT of incision site infection.

Abbreviations: Gl, gastrointestinal; HLT, high-level term; MedDRA, Medical Dictionary for Regulatory Activities; PT, preferred term; RR, relative risk; SMQs, standard MedDRA queries. 
Table 4 Occurrence of important safety risks among parecoxibtreated subjects (derived from postmarketing data based on $69,567,300$ standard units of parecoxib) ${ }^{\mathrm{a}}$

\begin{tabular}{|c|c|c|c|}
\hline Risk & $\begin{array}{l}\text { Total } \\
\text { (n) }\end{array}$ & $\begin{array}{l}\text { Serious } \\
\text { (n) }\end{array}$ & Outcome \\
\hline Gl-related event ${ }^{b}$ & 35 & 35 & $\begin{array}{l}\text { Recovered }=12 \\
\text { Recovering=3 } \\
\text { Not recovered }=4 \\
\text { Unknown }=12 \\
\text { Fatal }=4\end{array}$ \\
\hline $\begin{array}{l}\text { Renal failure and } \\
\text { impairment }^{c}\end{array}$ & 77 & 68 & $\begin{array}{l}\text { Recovered=32 } \\
\text { Recovering=9 } \\
\text { Recovering with sequela=I } \\
\text { Not recovered=8 } \\
\text { Unknown=2I } \\
\text { Fatal=6 }\end{array}$ \\
\hline $\begin{array}{l}\text { Embolic and } \\
\text { thrombotic } \\
\text { event }^{d}\end{array}$ & 66 & 64 & $\begin{array}{l}\text { Recovered }=20 \\
\text { Recovering=4 } \\
\text { Recovering with sequela=2 } \\
\text { Not recovered=2 } \\
\text { Unknown=18 } \\
\text { Fatal }=20\end{array}$ \\
\hline $\begin{array}{l}\text { Hypersensitivity } \\
\text { reaction }^{\mathrm{e}}\end{array}$ & 190 & 98 & $\begin{array}{l}\text { Recovered }=125 \\
\text { Recovering=I5 } \\
\text { Recovering with sequela=I } \\
\text { Not recovered=8 } \\
\text { Unknown=34 } \\
\text { Fatal=7 }\end{array}$ \\
\hline $\begin{array}{l}\text { Hypotension- } \\
\text { related events }\end{array}$ & 32 & 25 & $\begin{array}{l}\text { Recovered }=20 \\
\text { Recovering=3 } \\
\text { Unknown=6 } \\
\text { Fatal=3 }\end{array}$ \\
\hline $\begin{array}{l}\text { Severe } \\
\text { cutaneous } \\
\text { reactiong }\end{array}$ & 17 & 17 & $\begin{array}{l}\text { Recovered=9 } \\
\text { Recovering=l } \\
\text { Not recovered=2 } \\
\text { Unknown=3 } \\
\text { Fatal=2 }\end{array}$ \\
\hline $\begin{array}{l}\text { Masking signs of } \\
\text { inflammation }^{\mathrm{h}}\end{array}$ & 18 & 18 & $\begin{array}{l}\text { Recovered }=7 \\
\text { Recovering=I } \\
\text { Not recovered=3 } \\
\text { Unknown=3 } \\
\text { Fatal=4 }\end{array}$ \\
\hline
\end{tabular}

Notes: alncludes medically confirmed cases of each event through March 3I, 2014. 'Based on the MedDRA version I6.I SMQs of Gl hemorrhage, Gl perforation, and Gl ulceration. 'Based on the MedDRA version 16.1 HLT of renal failure and impairment. 'Based on the MedDRA version 16.I SMQs of embolic and thrombotic events arterial, embolic and thrombotic events venous, and embolic and thrombotic events vessel type unspecified and mixed arterial and venous. ${ }^{\text {eBased }}$ on the MedDRA version 16.I SMQ of hypersensitivity. 'Based on the MedDRA version I6.I

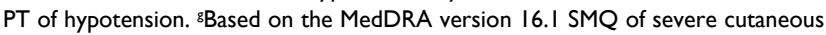
adverse reactions. "hased on the MedDRA version 16.1 serious AEs with a PT whose primary allocation is to the system organ class category of infections and infestations.

Abbreviations: AEs, adverse events; GI, gastrointestinal; HLT, high-level term; MedDRA, Medical Dictionary for Regulatory Activities; PT, preferred term; SMQs, standard MedDRA queries.

The low rate of cardiovascular events in the clinical trial database may be due to the short-term duration of the trials and the controlled manner in which injectable parecoxib is administered.
Because the cardiovascular risks observed in CABG surgery patients reflect the unique and highly dynamic prothrombotic and inflammatory syndrome that immediately follows cardiopulmonary bypass, the effects of parecoxib sodium in this population may not represent the effects of parecoxib sodium in surgical settings other than CABG surgery. Indeed, the mechanism of cardiovascular thromboembolic events after CABG surgery is not known and may be different from the mechanism of thrombotic events in other contexts of NSAID use. As a result, CABG surgery is now a contraindication to all NSAIDs, including COX-2 inhibitors.

Sixty-six medically confirmed cases were identified in the analysis of available postauthorization data, with over one-third of patients recovering from the event and nearly one-third associated with a report of a fatality (Table 4).

\section{Hypersensitivity reactions}

Hypersensitivity events, including anaphylactic reactions, angioedema, and allergic reactions, during and after surgery may arise from a number of causes, including the use of antibiotic treatments or perioperative analgesics, such as NSAIDs. ${ }^{17,18}$

The frequency of anaphylactic reactions was similar between parecoxib (8.7\%) and placebo (8.6\%) treatment groups in the analysis of clinical trial data (Table 3). Hypotension may result from the sudden release of relatively large amounts of vasoactive substances, such as histamine, from cells involved in acute hypersensitivity. The frequency of hypotension in the analysis of clinical trial data was $2.6 \%$ for the parecoxib group compared with $2.1 \%$ for placebo (Table 3). A majority of the cases of hypotension group were categorized as mild to moderate in severity, with only $0.2 \%$ of patients experiencing severe hypotension in each treatment group. Only 32 medically confirmed cases of hypotensionrelated events were identified in the postauthorization analysis, with 23 cases classified as recovered or recovering. Three fatalities were reported in the postauthorization analysis (Table 4).

The frequency of angioedema, including edema of the face, lips, genitalia, throat, and other structures, was similar between parecoxib (2.5\%) and placebo (2.8\%) groups in the clinical trial analysis (Table 3).

Severe cutaneous adverse reactions, such as erythema multiforme, exfoliative dermatitis, and Stevens-Johnson syndrome, are believed to be T-cell-mediated delayed hypersensitivity reactions. ${ }^{47}$ In some individuals, reactive metabolites of a drug combine with healthy tissue and incite a pathoimmunologic response that eventually leads to autoimmune 
Table 5 Risk difference (parecoxib vs placebo) of important safety risks during the 28 randomized placebo-controlled trials, adjusted for study

\begin{tabular}{|c|c|c|c|c|}
\hline Risk & $\begin{array}{l}\text { Parecoxib } \\
\text { (weighted \% of } \\
\text { patients) }\end{array}$ & $\begin{array}{l}\text { Placebo } \\
\text { (weighted \% of } \\
\text { patients) }\end{array}$ & $\begin{array}{l}\text { Weighted risk } \\
\text { difference }(95 \% \mathrm{Cl})\end{array}$ & $P$-value \\
\hline \multicolumn{5}{|l|}{ Gl-related event $^{\mathrm{a}}$} \\
\hline Hemorrhage & 0.16 & 0.14 & $0.02(-1.14,0.19)$ & 0.78 \\
\hline Perforation & 0.00 & 0.07 & $-0.07(-0.15,0.02)$ & 0.13 \\
\hline Ulceration & 0.17 & 0.05 & $0.12(-0.02,0.26)$ & 0.09 \\
\hline Renal failure and impairment ${ }^{\mathrm{b}, *}$ & 1.27 & 0.63 & $0.64(0.23,1.04)$ & $<0.01$ \\
\hline \multicolumn{5}{|l|}{ Embolic and thrombotic event ${ }^{c}$} \\
\hline Arterial & 0.37 & 0.20 & $0.18(-0.05,0.40)$ & 0.13 \\
\hline Venous & 0.19 & 0.14 & $0.05(-0.12,0.23)$ & 0.55 \\
\hline Mixed or unspecified & 0.21 & 0.16 & $0.06(-0.13,0.24)$ & 0.55 \\
\hline \multicolumn{5}{|l|}{ Hypersensitivity reaction } \\
\hline Anaphylactic (all types) $^{d}$ & 9.04 & 8.86 & $0.18(-1.03,1.39)$ & 0.77 \\
\hline Hypotension ${ }^{\mathrm{e}, * *}$ & 2.88 & 2.06 & $0.82(0.17,1.47)$ & 0.01 \\
\hline Angioedema (all types) ${ }^{f}$ & 2.67 & 2.53 & $0.14(-0.53,0.81)$ & 0.68 \\
\hline Severe cutaneous reaction ${ }^{g}$ & 0 & 0 & - & - \\
\hline \multicolumn{5}{|l|}{ Masking signs of inflammation } \\
\hline Skin and soft tissue infections ${ }^{h}$ & 0.00 & 0.10 & $-0.10(-0.20,0.00)$ & 0.06 \\
\hline Incision site infection ${ }^{i}$ & 0.02 & 0.00 & $0.02(-0.02,0.07)$ & 0.29 \\
\hline
\end{tabular}

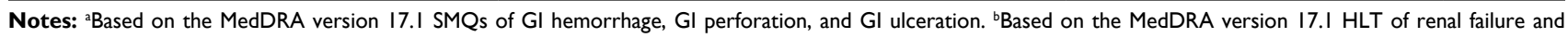
impairment. 'Based on the MedDRA version 17.I SMQs of embolic and thrombotic events arterial, embolic and thrombotic events venous, and embolic and thrombotic events vessel type unspecified and mixed arterial and venous. 'Based on the MedDRA version I7.I SMQ of anaphylactic reaction. ${ }^{\mathrm{e} B a s e d}$ on the MedDRA version I7.I PT

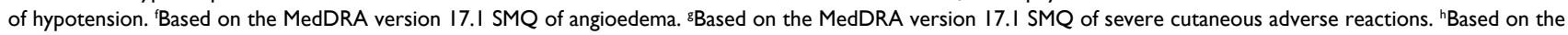
MedDRA version I7.I HLT of skin structures and soft tissue infections. 'Based on the MedDRA version 17.I PT of incision site infection. *A majority of the events in the renal failure impairment group were classified as oliguria. **A majority of cases of hypotension were classified as mild or moderate in severity.

Abbreviations: GI, gastrointestinal; HLT, high-level term; MedDRA, Medical Dictionary for Regulatory Activities; PT, preferred term; SMQs, standard MedDRA queries.

attack on the skin, with epidermal necrosis. No instances of severe cutaneous adverse reactions were reported in either the placebo or parecoxib treatment groups following analysis of the clinical trial database (Table 3). Seventeen medically confirmed cases of severe cutaneous adverse reactions were identified in analysis of the postauthorization data, with a majority of subjects $(n=10)$ having recovered or were recovering from this reaction (Table 4). Two fatalities were reported in the postauthorization analysis.

\section{Masking signs of inflammation}

Postoperative patients will experience inflammation while healing from incisions and invasive procedures that allow entry of pathogens. By reducing pain, fever, and swelling from inflammation, NSAIDs may delay recognition by patient as well as health care providers of a nascent infection capitalizing on the trauma of surgical incision. Thus, a diagnosis of infection may be delayed. Incision site or other skin/tissue infections, however, occurred in $<0.1 \%$ of patients in both treatment groups in the analysis of parecoxib clinical trial data (Table 3 ). Likewise, only 18 medically confirmed cases were reported in the postauthorization analysis, of which 8 were classified as recovered or recovering. Four cases were associated with the report of fatality in the postauthorization analysis (Table 4).

\section{Supplementary analyses of the clinical trial data}

Overall, the results of the supplementary analyses of the clinical trial data support the primary analyses demonstrating that the occurrence of most predefined safety events is low and comparable between the parecoxib and placebo treatment groups (Table 5). When adjusting for study, the only risks that differed between treatment groups (parecoxib vs placebo) in a statistically significant manner were those for renal failure and impairment and for hypotension.

The weighted percentage of patients reporting renal failure and impairment was $1.3 \%$ for parecoxib and $0.6 \%$ for placebo (risk difference $=0.635 ; 95 \% \mathrm{CI}=0.226,1.044$; $p=0.002$ ). The category of renal failure and impairment comprised six specific events. The occurrence of these events in the parecoxib groups was as follows: oliguria $(n=33)$, renal impairment $(n=11)$, renal failure $(n=7)$, acute renal failure $(n=2)$, anuria $(n=1)$, and pre-renal failure $(n=0)$. Of these six 
specific events, only the risk of oliguria significantly differed between the parecoxib and placebo groups (parecoxib $=0.8 \%$ and placebo $=0.4 \%$; weighted risk difference $=0.357 ; 95 \%$ $\mathrm{CI}=0.028,0.686 ; p=0.034)$.

The weighted percentage of patients reporting hypotension was $2.9 \%$ for parecoxib and $2.1 \%$ for placebo (risk difference $=0.822 ; 95 \% \mathrm{CI}=0.171,1.473 ; p=0.013$ ). However, there was no significant difference between the placebo and parecoxib groups when hypotension was analyzed according to severity level. The weighted percentage of patients reporting mild hypotension was $1.5 \%$ for parecoxib and $1.1 \%$ for placebo (risk difference $=0.429 ; 95 \% \mathrm{CI}=-0.046,0.904$; $p=0.077$ ); moderate hypotension was $1.2 \%$ for parecoxib and $0.9 \%$ for placebo (risk difference $=0.362 ; 95 \% \mathrm{CI}=-0.074$, $0.797 ; p=0.104$ ); and severe hypotension was $0.2 \%$ for parecoxib and $0.2 \%$ for placebo (risk difference $=0.073 ; 95 \%$ $\mathrm{CI}=-0.116,0.262 ; p=0.452)$.

\section{Discussion}

Nonselective NSAIDs that inhibit both COX-1 and COX-2 are effective for the management of pain and inflammation but have been associated with a variety of unwanted, potentially serious, side effects. Inhibitors that specifically target COX-2, such as parecoxib, have been developed to reduce the potential for some of these side effects. Specifically, an advantage of COX-2 inhibitors is their reduced potential for serious GI ulceration and bleeding compared with nonselective NSAIDs. ${ }^{12,13}$ Specific GI-related events occurred in $\sim 0.2 \%$ of parecoxib-treated patients in our analysis of 28 randomized controlled trials, confirming parecoxib's low GI toxicity profile. This profile compares favorably to other injectable, nonselective NSAIDs such as ketorolac, tenoxicam, and dexketoprofen. Both tenoxicam and dexketoprofen exhibit an intermediate risk for GI toxicity. ${ }^{48,49}$ Ketorolac, one of the most widely used NSAIDs for postoperative pain, is among the most GI toxic of all NSAIDs. ${ }^{48-50}$ Indeed, a headto-head study demonstrated that parecoxib has significantly less GI toxicity than IV ketorolac in healthy elderly subjects. ${ }^{51}$

In addition to low GI toxicity, our primary clinical trial analysis demonstrates that the risk of other specific prespecified safety events, commonly associated with COX inhibition, is low with parecoxib. Such events included renal failure and impairment, cardiovascular embolic and thrombotic events, a variety of hypersensitivity reactions, and masking signs of inflammation. Supplemental analysis of the clinical trial data, adjusting for study, generally supported the primary analysis but a statistically significant difference between the parecoxib and placebo treatment groups was evident for renal failure and impairment and for hypotension. However, the specific event under the category of renal failure and impairment that was most commonly reported (and the only one significantly different from placebo) was that of oliguria. More serious events such as anuria, renal failure, or pre-renal failure were not different between treatment groups. Likewise, though there was a significant difference between treatment groups for hypotension, a majority of these events in parecoxib-treated patients were classified as mild or moderate in severity, and the proportion of patients reporting severe hypotension was the same in both treatment groups $(0.2 \%)$.

These findings were supported by our analysis of the available postauthorization data. For nearly all predefined events, $<100$ cases were reported over the 13-year evaluation period in which nearly 70 million units of parecoxib were sold. Additionally, among reports with known outcomes, a majority of patients were classified as recovered or recovering from these events. As discussed in the "Methods" section, however, the postauthorization analysis is limited in that it is difficult to definitely attribute AEs and outcomes, including fatalities, to parecoxib due to the lack of a placebo comparison and the absence of certain data on a case-by-case basis.

Parecoxib is administered over a short period by a trained professional in a highly controlled setting, such as a hospital or surgical clinic, which likely contributes to the scarcity of potentially serious AEs in parecoxib-treated patients in both the clinical trial and postauthorization databases. This underscores the importance of following local labeling guidelines to avoid use in contraindicated patient populations, such as patients undergoing CABG. A complete and accurate evaluation of patients should be performed prior to administering parecoxib to identify patients who may be at risk for the safety events discussed here. The patients most at risk for GI-related events, for example, are the elderly; patients with cardiovascular disease; patients using concomitant aspirin; patients with positive Helicobacter pylori status; patients with a history of, or active, GI disease, such as ulceration, bleeding, dyspepsia, or inflammatory conditions; patients prescribed NSAIDs; patients using multiple NSAIDs; or patients using concomitant prescription drugs, such as corticosteroids and anticoagulants. However, the risk factors for GI ulceration events and their interaction with parecoxib have not been studied in clinical trials. Likewise, patients with a creatinine clearance $<30 \mathrm{~mL} / \mathrm{min}$ and patients predisposed to fluid retention may be at risk of worsening of renal function and, as such, parecoxib should be initiated at the lowest recommended dose and the patient's kidney 
function should be closely monitored. Continuous monitoring of patients throughout the treatment process will aid in the early identification and resolution of safety events that are difficult to predict or are not associated with any predetermined risk factors, such as hypersensitivity reactions and masking signs of inflammation.

Overall, the data presented here demonstrate that potentially serious safety events associated with COX-2 inhibitors and/or nonselective NSAIDs occur infrequently with parecoxib when administered in a controlled setting according to prescribing guidelines and thus highlight the safety of parecoxib in patients with postoperative pain.

\section{Acknowledgments}

Medical writing support was provided by Matt Soulsby, PhD, CMPP of Engage Scientific Solutions and was funded by Pfizer. The original studies included in this analysis were sponsored by Pfizer.

Preliminary versions/portions of these data were presented as poster presentations at the European Society of Anaesthesiology (ESA) Euroanaesthesia, May 30-June 2, 2015, Berlin, Germany, and May 28-30, 2016, London, UK.

\section{Disclosure}

Stephan A Schug reports that the Anesthesiology Unit of the University of Western Australia, but not SAS personally, has received research and travel funding, and speaking and consulting honoraria from Pfizer within the last 5 years. Bruce Parsons, Chunming Li, and Feng Xia are full-time employees of and own stock in Pfizer. The authors report no other conflicts of interest in this work.

\section{References}

1. Dwivedi AK, Gurjar V, Kumar S, Singh N. Molecular basis for non specificity of nonsteroidal anti-inflammatory drugs (NSAIDs). Drug Discov Today. 2015;20(7):863-873.

2. Rouzer CA, Marnett LJ. Cyclooxygenases: structural and functional insights. J Lipid Res. 2009;50(Suppl):S29-S34.

3. Ramsay MA. Acute postoperative pain management. Proc (Bayl Univ Med Cent). 2000;13(3):244-247.

4. The American Society of Anesthesiologists Task Force on Acute Pain Management. Practice guidelines for acute pain management in the perioperative setting: an updated report by the American Society of Anesthesiologists Task Force on Acute Pain Management. Anesthesiology. 2012;116(2):248-273.

5. Schug SA. The role of COX-2 inhibitors in the treatment of postoperative pain. J Cardiovasc Pharmacol. 2006;47 (Suppl 1):S82-S86.

6. Schafer AI. Effects of nonsteroidal antiinflammatory drugs on platelet function and systemic hemostasis. JClin Pharmacol. 1995;35(3):209-219.

7. Hernandez-Diaz S, Rodriguez LA. Association between nonsteroidal anti-inflammatory drugs and upper gastrointestinal tract bleeding/perforation: an overview of epidemiologic studies published in the 1990s. Arch Intern Med. 2000;160(14):2093-2099.
8. Allison MC, Howatson AG, Torrance CJ, Lee FD, Russell RI. Gastrointestinal damage associated with the use of nonsteroidal antiinflammatory drugs. N Engl J Med. 1992;327(11):749-754.

9. Hawkey CJ. COX-1 and COX-2 inhibitors. Best Pract Res Clin Gastroenterol. 2001;15(5):801-820.

10. Weir MR. Renal effects of nonselective NSAIDs and coxibs. Cleve Clin J Med. 2002;69 (Suppl 1):SI53-S58.

11. Rostom A, Muir K, Dube C, et al. Gastrointestinal safety of cyclooxygenase-2 inhibitors: a cochrane collaboration systematic review. Clin Gastroenterol Hepatol. 2007;5(7):818-828.

12. Moore RA, Derry S, McQuay HJ. Cyclo-oxygenase-2 selective inhibitors and nonsteroidal anti-inflammatory drugs: balancing gastrointestinal and cardiovascular risk. BMC Musculoskelet Disord. 2007;8(1):73.

13. Leese PT, Hubbard RC, Karim A, et al. Effects of celecoxib, a novel cyclooxygenase-2 inhibitor, on platelet function in healthy adults: a randomized, controlled trial. J Clin Pharmacol. 2000;40(2): $124-132$.

14. Noveck R, Laurent A, Kuss M, Talwalker S, Hubbard R. Parecoxib sodium does not impair platelet function in healthy elderly and nonelderly individuals. Clin Drug Investig. 2001;21(7):465-476.

15. Murray MD, Brater DC. Renal toxicity of the nonsteroidal anti-inflammatory drugs. Annu Rev Pharmacol Toxicol. 1993;33(1):435-465.

16. Bello AE, Holt RJ. Cardiovascular risk with non-steroidal anti-inflammatory drugs: clinical implications. Drug Saf. 2014;37(11):897-902.

17. Kowalski ML, Makowska JS. Seven steps to the diagnosis of NSAIDs hypersensitivity: how to apply a new classification in real practice? Allergy Asthma Immunol Res. 2015;7(4):312-320.

18. Ortega N, Dona I, Moreno E, et al. Practical guidelines for diagnosing hypersensitivity reactions to nonsteroidal anti-inflammatory drugs. J Investig Allergol Clin Immunol. 2014;24(5):308-323.

19. Whelton A, Hamilton CW. Nonsteroidal anti-inflammatory drugs: effects on kidney function. J Clin Pharmacol. 1991;31(7):588-598.

20. Patrono C, Baigent C. Nonsteroidal anti-inflammatory drugs and the heart. Circulation. 2014;129(8):907-916.

21. Sherve K, Gerard CJ, Neher JO, St Anna L. Cardiovascular effects of NSAIDs. Am Fam Physician. 2014;90(4):Online.

22. European Medicines Agency. Summary of product characteristics. Available from: http://www.ema.europa.eu/docs/en_GB/document_library/ EPAR_-_Product_Information/human/000381/WC500038843.pdf. Accessed September 19, 2015.

23. Pfizer Australia. Dynastat prescribing information. Available from: http://www.pfizer.com.au/sites/g/files/g10005016/f/201311/PI_Dynastat_306.pdf. Accessed September 17, 2015.

24. Viscusi ER, Gimbel JS, Halder AM, et al. A multiple-day regimen of parecoxib sodium $20 \mathrm{mg}$ twice daily provides pain relief after total hip arthroplasty. Anesth Analg. 2008;107(2):652-660.

25. Nussmeier NA, Whelton AA, Brown MT, et al. Safety and efficacy of the cyclooxygenase- 2 inhibitors parecoxib and valdecoxib after noncardiac surgery. Anesthesiology. 2006;104(3):518-526.

26. Hubbard RC, Naumann TM, Traylor L, Dhadda S. Parecoxib sodium has opioid-sparing effects in patients undergoing total knee arthroplasty under spinal anaesthesia. Br J Anaesth. 2003;90(2):166-172.

27. Malan TP, Jr., Gordon S, Hubbard R, Snabes M. The cyclooxygenase2-specific inhibitor parecoxib sodium is as effective as $12 \mathrm{mg}$ of morphine administered intramuscularly for treating pain after gynecologic laparotomy surgery. Anesth Analg. 2005;100(2):454-460.

28. Ott E, Nussmeier NA, Duke PC, et al. Efficacy and safety of the cyclooxygenase 2 inhibitors parecoxib and valdecoxib in patients undergoing coronary artery bypass surgery. J Thorac Cardiovasc Surg. 2003;125(6):1481-1492.

29. Joshi GP, Viscusi ER, Gan TJ, et al. Effective treatment of laparoscopic cholecystectomy pain with intravenous followed by oral COX-2 specific inhibitor. Anesth Analg. 2004;98(2):336-342.

30. Snabes MC, Jakimiuk AJ, Kotarski J, et al. Parecoxib sodium administered over several days reduces pain after gynecologic surgery via laparotomy. J Clin Anesth. 2007;19(6):448-455. 
31. Rasmussen GL, Steckner K, Hogue C, Torri S, Hubbard RC. Intravenous parecoxib sodium for acute pain after orthopedic knee surgery. Am J Orthop (Belle Mead NJ). 2002;31(6):336-343.

32. Barton SF, Langeland FF, Snabes MC, et al. Efficacy and safety of intravenous parecoxib sodium in relieving acute postoperative pain following gynecologic laparotomy surgery. Anesthesiology. 2002;97(2):306-314

33. Bikhazi GB, Snabes MC, Bajwa ZH, et al. A clinical trial demonstrates the analgesic activity of intravenous parecoxib sodium compared with ketorolac or morphine after gynecologic surgery with laparotomy. Am J Obstet Gynecol. 2004;191(4):1183-1191.

34. Desjardins PJ, Grossman EH, Kuss ME, et al. The injectable cyclooxygenase-2-specific inhibitor parecoxib sodium has analgesic efficacy when administered preoperatively. Anesth Analg. 2001;93(3):721-727.

35. Malan TP, Jr., Marsh G, Hakki SI, et al. Parecoxib sodium, a parenteral cyclooxygenase 2 selective inhibitor, improves morphine analgesia and is opioid-sparing following total hip arthroplasty. Anesthesiology. 2003;98(4):950-956.

36. Tang J, Li S, White PF, et al. Effect of parecoxib, a novel intravenous cyclooxygenase type- 2 inhibitor, on the postoperative opioid requirement and quality of pain control. Anesthesiology. 2002;96(6):1305-1309.

37. Nussmeier NA, Whelton AA, Brown MT, et al. Complications of the COX-2 inhibitors parecoxib and valdecoxib after cardiac surgery. N Engl J Med. 2005;352(11):1081-1091.

38. Apfelbaum JL, Desjardins PJ, Brown MT, Verburg KM. Multiple-day efficacy of parecoxib sodium treatment in postoperative bunionectomy pain. Clin J Pain. 2008;24(9):784-792.

39. Daniels SD, Grossman EH, Kuss ME, et al. A Double-Blind, Randomized Comparison of Intramuscularly and Intravenously Administered Parecoxib Sodium Versus Ketorolac and Placebo in a Post-Oral Surgery Pain Model. Clin Ther. 2001;23:1018-1031.

40. Mehlisch DR, Desjardins PJ, Daniels S, Hubbard RC. Single doses of parecoxib sodium intravenously are as effective as ketorolac in reducing pain after oral surgery. J. Oral Maxillofac. Surg. 2003; 61(9):1030.
41. Mehlisch DR, Desjardins PJ, Daniels S, Hubbard RC. The analgesic efficacy of intramuscular parecoxib sodium in postoperative dental pain. J Am Dental Assoc. 2004;135:1578-1590.

42. Agresti A, Hartzel J. Strategies for comparing treatments on a binary response with multi-centre data. Stat Med. 2000;19(8):1115-1139.

43. Matsui H, Shimokawa O, Kaneko T, et al. The pathophysiology of nonsteroidal anti-inflammatory drug (NSAID)-induced mucosal injuries in stomach and small intestine. J Clin Biochem Nutr. 2011;48(2): 107-111.

44. Harris RC. COX-2 and the kidney. J Cardiovasc Pharmacol. 2006;47 (Suppl 1):S37-S42.

45. Bakr M, Waller D. COX-2 inhibitors and the cardiovascular system: is there a class effect? Br J Cardiol. 2005;12(5):387-391.

46. Schug SA, Joshi GP, Camu F, Pan S, Cheung R. Cardiovascular safety of the cyclooxygenase- 2 selective inhibitors parecoxib and valdecoxib in the postoperative setting: an analysis of integrated data. Anesth Analg. 2009;108(1):299-307.

47. Lin YF, Yang $\mathrm{CH}$, Sindy $\mathrm{H}$, et al. Severe cutaneous adverse reactions related to systemic antibiotics. Clin Infect Dis. 2014;58(10) 1377-1385.

48. Castellsague J, Riera-Guardia N, Calingaert B, et al. Individual NSAIDs and upper gastrointestinal complications: a systematic review and meta-analysis of observational studies (the SOS project). Drug Saf. 2012;35(12):1127-1146.

49. Laporte JR, Ibanez L, Vidal X, Vendrell L, Leone R. Upper gastrointestinal bleeding associated with the use of NSAIDs: newer versus older agents. Drug Saf. 2004;27(6):411-420.

50. Bjarnason I. Gastrointestinal safety of NSAIDs and over-the-counter analgesics. Int J Clin Pract Suppl. 2013;67(s178):37-42.

51. Stoltz RR, Harris SI, Kuss ME, et al. Upper GI mucosal effects of parecoxib sodium in healthy elderly subjects. Am J Gastroenterol. 2002;97(1) $65-71$

\section{Journal of Pain Research}

\section{Publish your work in this journal}

The Journal of Pain Research is an international, peer reviewed, open access, online journal that welcomes laboratory and clinical findings in the fields of pain research and the prevention and management of pain. Original research, reviews, symposium reports, hypothesis formation and commentaries are all considered for publication.

\section{Dovepress}

The manuscript management system is completely online and includes a very quick and fair peer-review system, which is all easy to use. Visit http://www.dovepress.com/testimonials.php to read real quotes from published authors. 